\title{
Combination of bortezomib and daunorubicin in the induction of apoptosis in T-cell acute lymphoblastic leukemia
}

\author{
XIN DU $^{1 *}$, JIA TONG $^{1 *}$, HONGYING LU $^{1 *}$, CONG HE $^{1}$, SHENGHONG DU $^{1}$, PEIMIN JIA $^{1}$, WEILI ZHAO ${ }^{1}$, \\ HANZHANG XU ${ }^{2}$, JUNMIN LI ${ }^{1}$, ZHIXIANG SHEN ${ }^{1}$, YINGLI WU ${ }^{2}$, JIANHUA TONG ${ }^{1}$ and LI ZHOU ${ }^{1}$ \\ ${ }^{1}$ State Key Laboratory of Medical Genomics, Department of Hematology, Faculty of Medical Laboratory Science, \\ Ruijin Hospital, Shanghai Jiaotong University School of Medicine; ${ }^{2}$ Hongqiao International Institute of Medicine, \\ Shanghai Tongren Hospital/Faculty of Basic Medicine, Department of Pathophysiology, Chemical Biology Division \\ of Shanghai Universities E-Institutes, Key Laboratory of Cell Differentiation and Apoptosis of The Chinese Ministry \\ of Education, Shanghai Jiaotong University School of Medicine, Shanghai 200025, P.R. China
}

Received March 19, 2016; Accepted February 27, 2017

DOI: $10.3892 / \mathrm{mmr} .2017 .6554$

\begin{abstract}
Despite advances in the treatment of T-cell acute lymphoblastic leukemia (T-ALL), the outcome of T-ALL treatment remains unsatisfactory, therefore, more effective treatment is urgently required. The present study examined the cytotoxicities of bortezomib in combination with daunorubicin against human Jurkat and Molt-4 T-ALL cells and primary T-ALL cells. Compared with treatment alone, co-exposure of cells to bortezomib and daunorubicin resulted in a significant increase in cell death in the Jurkat cells, as evidenced by the increased percentage of Annexin V-positive cells, the formation of apoptotic bodies. In addition, the administration sequence of bortezomib and daunorubicin had an effect on cell viability. Treatment with bortezomib followed by daunorubicin treatment was more effective, compared with treatment with daunorubicin followed by bortezomib. Co-treatment with bortezomib and daunorubicin markedly enhanced the activation of caspase- $3,-8$ and -9 , which was reversed by the pan-caspase inhibitor, Z-VAD-FMK. In addition, cotreatment with bortezomib and daunorubicin enhanced the collapse of mitochondrial transmembrane potential and upregulated the proapoptotic protein, B-cell lymphoma 2 (Bcl-2)-interacting mediator of cell death (Bim), but not Bcl-2 or Bcl-extra large. Consistent with this, it was demonstrated that cotreatment of bortezomib and daunorubicin efficiently induced apoptosis in
\end{abstract}

Correspondence to: Dr Li Zhou or Professor Jianhua Tong, State Key Laboratory of Medical Genomics, Department of Hematology, Faculty of Medical Laboratory Science, Ruijin Hospital, Shanghai Jiaotong University School of Medicine, 197 Ruijin Er Road, Shanghai 200025, P.R. China

E-mail: lizhou99_99@163.com

E-mail: jh_tong@126.com

*Contributed equally

Key words: bortezomib, daunorubicin, T-cell acute lymphoblastic leukemia, mitochondrial transmembrane potential primary T-ALL cells, and cell death was associated with the collapse of mitochondrial transmembrane potential and the upregulation of Bim. Taken together, these findings indicated that the combination of bortezomib and daunorubicin significantly enhanced their apoptosis-inducing effect in T-ALL cells, which may warrant further investigation in preclinical and clinical investigations.

\section{Introduction}

T-cell acute lymphoblastic leukemia (T-ALL) is an aggressive hematologic disease (1), accounting for $\sim 15$ and $25 \%$ of ALL in pediatric and adult patients, respectively (2). Despite progress in treatment and children having an approximate cure rate of $90 \%$, the cure rate of adults is $<50 \%$, even with hematopoietic stem cell transplantation (3). In adult patients with ALL who have achieved complete remission, the majority relapse, and few patients are cured even when treated using the best therapeutic regimens currently available. Therefore, more effective treatment is urgently required for this disease.

The $26 \mathrm{~S}$ proteasome is vital in eukaryotic cell function and viability. It is responsible for several integral cellular processes, including the timely degradation of cell cycle regulator proteins and transcription factors, and the maintenance of cellular homeostasis, all of which are essential for cell proliferation, differentiation apoptosis and angiogenesis (4). The proteasome has consequently become an attractive target for therapeutic intervention in cancer chemotherapy. Bortezomib (Velcade; PS-341), a dipeptide boronic acid analog and the first clinically available proteasome inhibitor, has been widely applied to treat multiple myeloma (5). The drug exhibits selectivity towards the proteasome of cancer cells, rendering it with a distinct therapeutic advantage. Preclinical studies have shown that bortezomib also induces apoptosis in acute leukemia and solid tumor cells (6). However, as a single agent, the clinical results of bortezomib in patients with acute myeloid leukemia and pediatric refractory ALL are less encouraging (7). Accumulating clinical studies have indicated that the effect of bortezomib combined with anthracycline drugs, including idarubicin and doxorubicin, is likely to be 
active with acceptable toxicity in hematological malignancies, including acute leukemia (8-10). Daunorubicin belongs to the anthracycline family, and is one of the major antitumor agents in the treatment of myeloid leukemia (11). Daunorubicin kills leukemic cells by the inhibition of topoisomerase II, induction of DNA damage and generation of reactive oxygen species (ROS) (12). However, whether the combination of daunorubicin and bortezomib is also effective in T-ALL cells remains to be elucidated.

In the present study, the cytotoxicities against T-ALL cells of bortezomib and daunorubicin, alone and in combination were compared. It was found that cotreatment of daunorubicin and bortezomib was more effective, compared with either agent used alone at inducing T-ALL cell death, and it was demonstrated that the mitochondrial pathway was important in this process.

\section{Materials and methods}

Cells and drug treatments. The T-ALL Jurkat and Molt-4 cells and Burkitt lymphoma Daudi cells (both from American Type Culture Collection; ATCC, Manassas, VA, USA) were maintained at $37^{\circ} \mathrm{C}$ in RPMI-1640 medium (Gibco; Thermo Fisher Scientific, Waltham, MA, USA) supplemented with $10 \%$ heat-inactivated fetal bovine serum (FBS; HyClone, Logan, UT, USA) in a humidified atmosphere containing $95 \%$ air and $5 \% \mathrm{CO}_{2}$. Primary ALL cells were harvested from bone marrow samples of 5 patients with T-ALL in Ruijin Hosptial (Shanghai, China), from October 2013 to July 2014 (patient information is shown in Table I). Bone marrow mononuclear cells were isolated using Ficoll-Paque isolation solution and centrifugation for $30 \mathrm{~min}$ at $400 \mathrm{x} \mathrm{g}$ at $25^{\circ} \mathrm{C}$ and re-suspended in RPMI-1640 medium supplemented with 10\% FBS. The study protocol was approved by the local institution review board at Shanghai Jiaotong University School of Medicine (Shanghai, China) and informed consent was obtained from the patients. Cells were seeded at $5 \times 10^{5}$ cells $/ \mathrm{ml}$ in 6 -well plates. Jurkat cells were treated with $10 \mathrm{nM}$ bortezomib (Velcade; Millennium Pharmaceutical, Cambridge, MA, USA) or $1 \mu \mathrm{M}$ daunorubicin hydrochloride (Sigma-Aldrich; Merck KGaA, Darmstadt, Germany), and Molt-4 cells were treated with $15 \mathrm{nM}$ bortezomib or $15 \mathrm{nM}$ daunorubicin hydrochloride, alone or in combination, for $24 \mathrm{~h}$ or $48 \mathrm{~h}$ in a humidified atmosphere containing $95 \%$ air and $5 \% \mathrm{CO}_{2}$.

Cell proliferation assays. The cells were seeded at $2-3 \times 10^{5}$ cells $/ \mathrm{ml}$ in a 6 -well plate and were treated with the appropriate drugs. The cells were counted every $12 \mathrm{~h}$ using a Beckman Coulter counter (Beckman Coulter, Inc., Fullerton, CA, USA) and cellular morphology was evaluated using light microscopy with Wright's staining. The experiment was performed in duplicate at least three times independently.

Apoptotic assays. For the apoptotic assays, $2 \times 10^{6}$ cells were washed twice with phosphate-buffered saline (PBS), and then labeled using Annexin V-fluorescein isothiocyanate and propidium iodide (PI) according to the manufacturer's protocol (BD Pharmingen, San Diego, CA, USA). Fluorescence intensity was measured using flow cytometry (BD Biosciences, Franklin Lakes, NJ, USA). Data were analyzed using CellQuest software (version 3.3; BD Biosciences). For each analysis, 10,000 events were recorded. The experiment was performed in duplicate at least three times independently.

Determination of mitochondrial membrane potential $(\Delta \Psi m)$. For measurement of alterations in $\Delta \Psi \mathrm{m}$, the cells $\left(1 \times 10^{6}\right)$ were incubated with $100 \mu \mathrm{g} / \mathrm{ml}$ Rhodamine 123 for $30 \mathrm{~min}$ at room temperature with $50 \mu \mathrm{g} / \mathrm{ml}$ PI. Fluorescence intensity was measured using flow cytometry. The experiment was performed at least three times independently in triplicate.

Western blot analysis. The cells were washed with PBS and lysed with lysis buffer containing $62.5 \mathrm{mM}$ Tris- $\mathrm{HCl}$ ( $\mathrm{pH} 6.8$ ), $100 \mathrm{mM}$ DTT, $2 \%$ SDS and $10 \%$ glycerol by boiling at $100^{\circ} \mathrm{C}$ for $5 \mathrm{~min}$. The cell lysates were centrifuged at $20,000 \mathrm{x} \mathrm{g}$ for $10 \mathrm{~min}$ at $4^{\circ} \mathrm{C}$, and proteins in the supernatants were quantified using a bicinchoninic acid protein assay (Merck KGaA). Protein extracts (10-20 $\mu \mathrm{g})$ were equally loaded to an 8-14\% SDS-polyacrylamide gel, electrophoresed, and transferred onto nitrocellulose membrane (GE Healthcare Life Sciences, Buckinghamshire, UK). The blots were stained with $0.2 \%$ Ponceau $\mathrm{S}$ red to ensure equal protein loading. Following blocking with 5\% nonfat milk in PBS, the membranes were probed with antibodies against caspase-3 (cat. no. 9662), caspase-8 (cat. no. 9746), caspase-9 (cat. no. 9502), Bim (cat. no. 2933), Bcl-2 (cat. no. 4223) and Bcl-xl (cat. no. 2764), overnight at $4^{\circ} \mathrm{C}$ (all at 1:1,000 dilution; Cell Signaling Technology, Inc., Danvers, MA, USA), then followed by incubation with horseradish peroxidase (HRP)-linked secondary antibodies (1:2,000 dilution; Cell Signaling Technology, Inc.) for $1 \mathrm{~h}$ at room temperature. The signals were detected using a chemiluminescence phototope-HRP kit (Cell Signaling Technology, Inc.) according to the manufacturer's protocol. As necessary, the blots were stripped and re-probed with anti- $\beta$-actin antibody (1:5,000 dilution; cat. no. PM053; Medical and Biological Laboratories Co., Ltd., Nagoya, Japan) as an internal control. All experiments were repeated three times.

Statistical analysis. Statistical analysis was performed using SPSS software (version 17.0; SPSS, Inc., Chicago, IL, USA). Student's t-test was used to compare differences between two groups. $\mathrm{P}<0.05$ was considered to indicate a statistically significant difference. Synergistic interactions between bortezomib and daunorubicin were analyzed by the Chou-Talalay method using CalcuSyn software version 2.1 (Biosoft, Cambridge, UK) (13). A combination index (CI) of $<1$, equal to 1 , and $>1$ indicate synergistic, additive and antagonistic effects, respectively.

\section{Results}

Bortezomib and daunorubicin cotreatment promotes late apoptosis of Jurkat and Molt-4 cells. The present study first examined the possible combinatorial effect of bortezomib and daunorubicin against Jurkat and Molt-4 cells. The Jurkat cells were treated with $1 \mu \mathrm{M}$ daunorubicin in the presence or absence of $10 \mathrm{nM}$ bortezomib. Bortezomib and daunorubicin alone caused a $24.9 \pm 0.74$ and a $72.6 \pm 2.17 \%$ reduction in the proliferation of Jurkat cells $48 \mathrm{~h}$ post treatment, respectively. The 
Table I. Information of patients with T-cell acute lymphoblastic leukemia.

\begin{tabular}{llcccc}
\hline Number & Sex & Age (years) & Blast $(\%)$ & Chromosome & White blood cells (x 10\%/l) \\
\hline 1 & Male & 16 & 95.5 & ND & 15.4 \\
2 & Female & 37 & 85.0 & ND & 2.2 \\
3 & Female & 24 & 91.5 & $51-53$, XX,3p-, del $(6)$, & 22.1 \\
4 & Female & 14 & 95.0 & $46, X X$ & 15.6 \\
5 & Female & 37 & 90.0 & $46, X X, 3 \mathrm{p}+$, del(9), & 32.3 \\
\hline
\end{tabular}

A

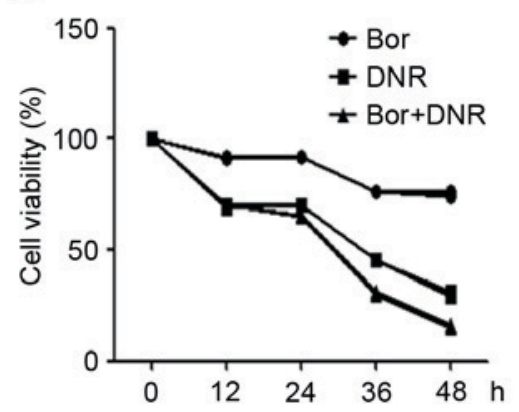

C

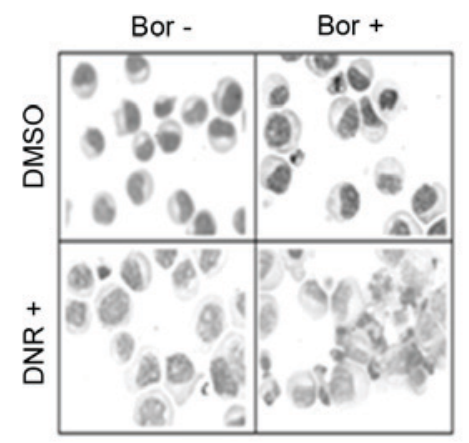

B

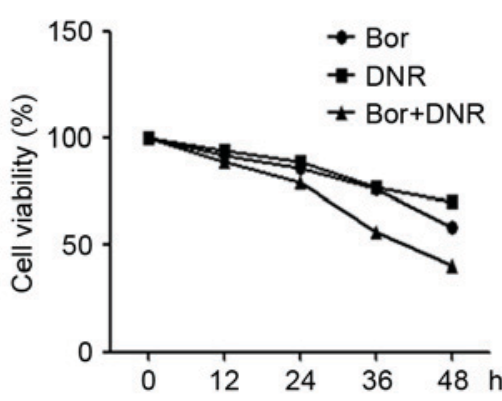

D

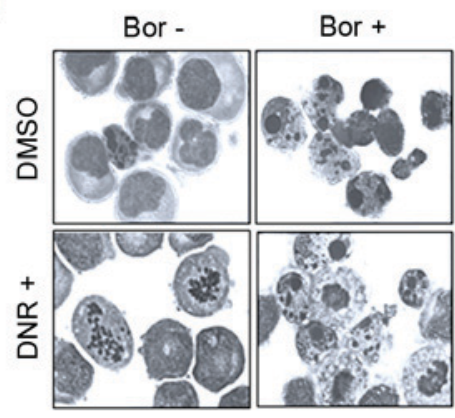

$\mathrm{F}$

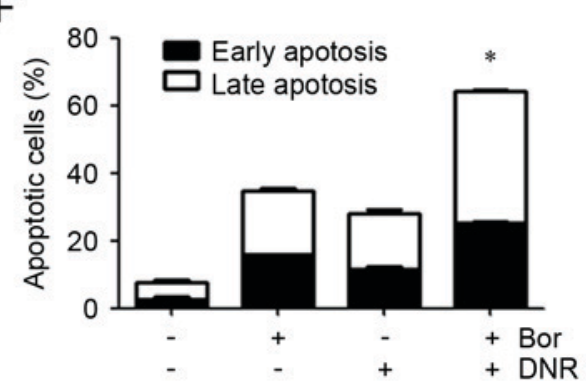

Figure 1. Effects of Bor+DNR on the proliferation of Jurkat and Molt-4 cells. (A) Jurkat cells were treated with $10 \mathrm{nM}$ Bor with or without $1 \mu \mathrm{M}$ DNR, and (B) Molt-4 cells were treated with $15 \mathrm{nM}$ Bor, with or without $15 \mathrm{nM}$ DNR for 12, 24, 36 and $48 \mathrm{~h}$, respectively, and cell viability was determined. The morphology of the (C) Jurkat and (D) Molt-4 cells treated with Bor, with or without DNR, was examined using Wright's staining (magnification, x100). Apoptotic cells were determined for (E) Jurkat and (F) Molt-4 cells treated with Bor, with or without DNR, for 24 h, by Annexin V/propidium iodide staining. All values are expressed as the mean \pm standard deviation. Each experiment was performed at least 3 times independently. ${ }^{*} \mathrm{P}<0.05$, compared with Bor or DNR treatment. Bor, bortezomib; DNR, daunorubincin.

combined use of the two agents resulted in a marked decrease in the proliferation of the Jurkat cells $(90.1 \pm 3.23 \%$; Fig. 1A), with similar results observed in the Molt-4 cells (Fig. 1B).

Wright's staining of the Jurkat cells treated with bortezomib $(10 \mathrm{nM})$ and daunorubicin $(1 \mu \mathrm{M})$ alone or in combination for $24 \mathrm{~h}$ showed that an induction of apoptosis was observed in the combination group, with the appearance of cell shrinkage, nuclear condensation and the formation of apoptotic bodies (Fig. 1C and D). Flow cytometric analysis revealed that, following treatment for $24 \mathrm{~h}$, the percentage of early apoptotic Jurkat cells treated with bortezomib was $24.2 \pm 6.35 \%$ ( $\mathrm{P}<0.05$, vs. control) whereas the percentage of late apoptotic Jurkat cells was $2.8 \pm 5.65 \%$ ( $P>0.05$, vs. control; Fig. 1E). The percentage of early apoptotic Jurkat 
Table II. Combination index values of bortezomib and daunorubicin in Jurkat cells.

\begin{tabular}{lccc}
\hline $\begin{array}{l}\text { Dose } \\
\text { bortezomib } \\
(\mathrm{nM})\end{array}$ & $\begin{array}{c}\text { Dose } \\
\text { daunorubicin } \\
(\mu \mathrm{M})\end{array}$ & $\begin{array}{c}\text { Growth } \\
\text { inhibition } \\
(\%)\end{array}$ & $\begin{array}{c}\text { Combination } \\
\text { index }\end{array}$ \\
\hline 10.0 & 1.00 & 52 & 0.31398 \\
10.0 & 1.25 & 58 & 0.33839 \\
10.0 & 1.50 & 64 & 0.34315 \\
15.0 & 10.00 & 70 & 0.29281 \\
15.0 & 10.25 & 84 & 0.12266 \\
15.0 & 10.50 & 78 & 0.40632 \\
20.0 & 1.00 & 40 & 0.66699 \\
20.0 & 1.25 & 62 & 0.47163 \\
20.0 & 1.50 & 70 & 0.38763 \\
\hline
\end{tabular}

Table III. Combination index values of bortezomib and daunorubicin in Molt-4 cells.

\begin{tabular}{lccc}
\hline $\begin{array}{l}\text { Dose } \\
\text { bortezomib } \\
(\mathrm{nM})\end{array}$ & $\begin{array}{c}\text { Dose } \\
\text { daunorubicin } \\
(\mathrm{nM})\end{array}$ & $\begin{array}{c}\text { Growth } \\
\text { inhibition } \\
(\%)\end{array}$ & $\begin{array}{c}\text { Combination } \\
\text { index }\end{array}$ \\
\hline 12.5 & 10.0 & 62 & 0.79070 \\
12.5 & 12.5 & 72 & 0.62921 \\
12.5 & 15.0 & 73 & 0.77304 \\
15.0 & 10.0 & 70 & 0.68773 \\
15.0 & 12.5 & 73 & 0.69217 \\
15.0 & 15.0 & 80 & 0.62526 \\
17.5 & 10.0 & 72 & 0.72619 \\
17.5 & 12.5 & 76 & 0.68364 \\
17.5 & 15.0 & 80 & 0.68750 \\
\hline
\end{tabular}

Table IV. Combination index values of bortezomib and daunorubicin in Daudi cells.

\begin{tabular}{lccc}
\hline $\begin{array}{l}\text { Dose } \\
\text { bortezomib } \\
(\mathrm{nM})\end{array}$ & $\begin{array}{c}\text { Dose } \\
\text { daunorubicin } \\
(\mathrm{nM})\end{array}$ & $\begin{array}{c}\text { Growth } \\
\text { inhibition } \\
(\%)\end{array}$ & $\begin{array}{c}\text { Combination } \\
\text { index }\end{array}$ \\
\hline 10.0 & 40.0 & 51 & 1.13996 \\
10.0 & 50.0 & 64 & 0.90496 \\
10.0 & 60.0 & 67 & 1.03848 \\
15.0 & 40.0 & 53 & 1.12142 \\
15.0 & 50.0 & 68 & 0.82208 \\
15.0 & 60.0 & 63 & 1.40427 \\
20.0 & 40.0 & 61 & 0.93591 \\
20.0 & 50.0 & 70 & 0.83512 \\
20.0 & 60.0 & 71 & 0.99927 \\
\hline
\end{tabular}

cells treated with daunorubicin was $12.4 \pm 2.75 \%(\mathrm{P}<0.05$, vs. control) whereas the percentage of late apoptotic Jurkat cells
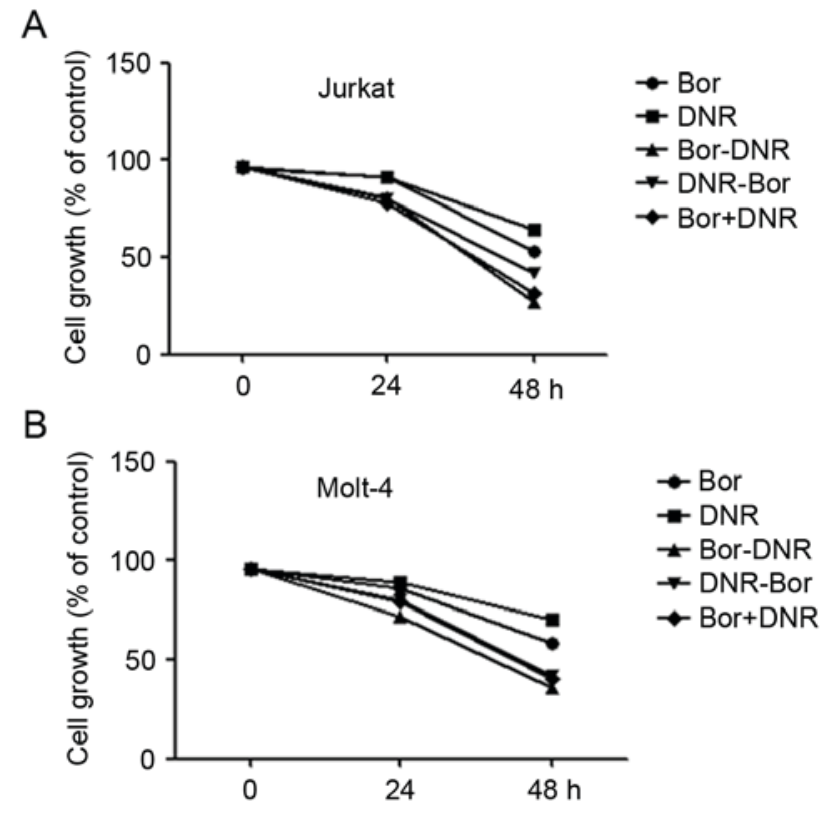

Figure 2. Effect of the sequences of Bor and DNR administration on the viability of Jurkat and Molt-4 cells. (A) Jurkat and (B) Molt-4 cells were treated with Bor for $12 \mathrm{~h}$, and then incubated with DNR until $48 \mathrm{~h}$, or were treated with DNR for $12 \mathrm{~h}$ followed by incubation with Bor until $48 \mathrm{~h}$. Cell viabilities were determined. Each experiment was performed at least 3 times independently. Bor, bortezomib; DNR, daunorubincin.

was $5.8 \pm 2.55 \%$ ( $\mathrm{P}>0.05$, vs. control; Fig. 1E). The combination of daunorubicin and bortezomib caused no apparent increase in the percentage of early apoptotic cells, compared with the cells treated with daunorubicin alone $(27.9 \pm 4.81 \%$; $\mathrm{P}>0.05)$, however, a significant increase in the percentage of late apoptotic cells was observed $(23.0 \pm 4.51 \%$; $\mathrm{P}<0.05$, vs. daunorubicin or bortezomib alone; Fig. 1E). Similar results were observed in the Molt-4 cells (Fig. 1F). These data indicated that the combination of daunorubicin and bortezomib enhanced the late apoptosis of Jurkat and Molt- 4 cells.

To determine whether these two drugs synergistically inhibited the proliferation of leukemia cells, the CI values were calculated using the Chou-Talalay method. As shown in Tables II-IV, daunorubicin and bortezomib cotreatment had a synergistic effect on the Jurkat and Molt-4, but not on the Daudi cells.

To determine whether the administration sequence affected the combination effect of daunorubicin and bortezomib, daunorubicin or bortezomib was added prior to, or following, the other drug. As shown in Fig. 2A and B, bortezomib treatment followed by daunorubicin was more effective, compared with daunorubicin treatment followed by bortezomib, or with the two drugs simultaneously.

Bortezomib promotes cell death by activating the caspase cascade. To investigate the mechanisms underlying bortezomib+daunorubicin-induced cell death in the Jurkat and Molt- 4 cells, the present study examined the activation of caspase using western blot analysis. It was found that cotreatment of the Jurkat (Fig. 3A) and Molt-4 (Fig. 3B) cells with daunorubicin and bortezomib significantly increased the levels of cleaved caspase- $3,-8$ and -9 . To determine the role of caspase activation, the Jurkat (Fig. 3C) and Molt-4 (Fig. 3D) cells were 
A

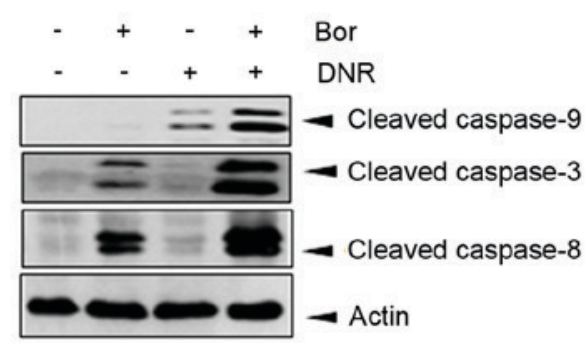

B

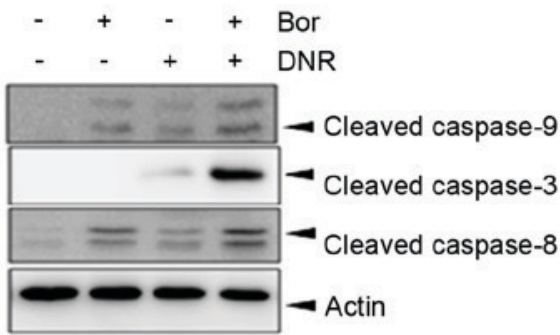

C

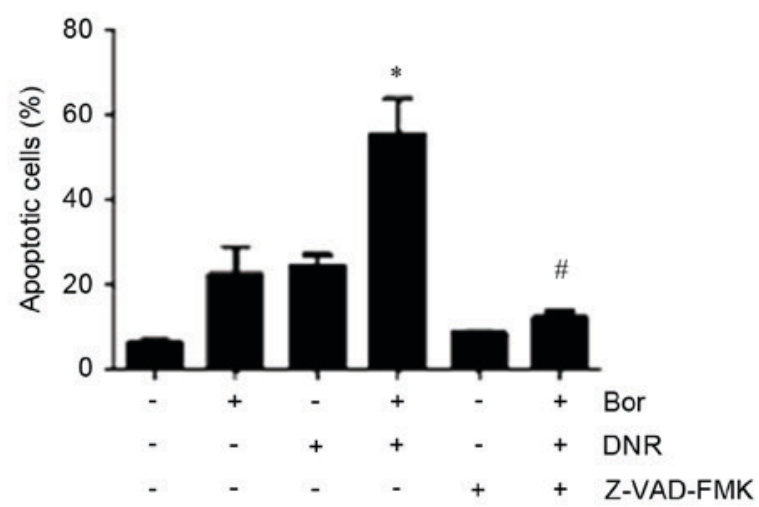

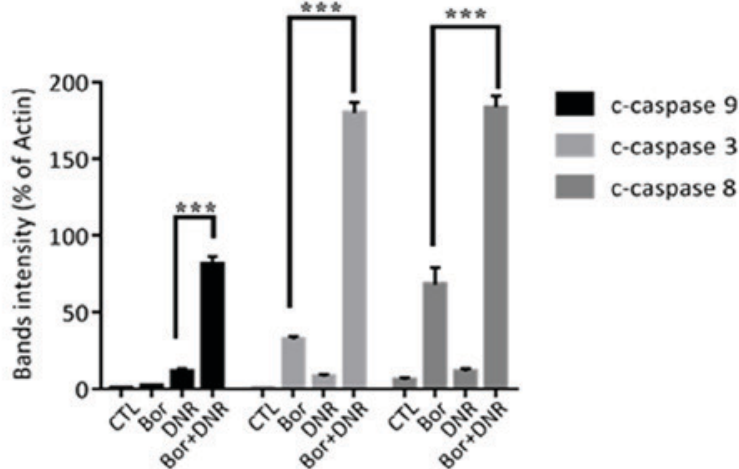

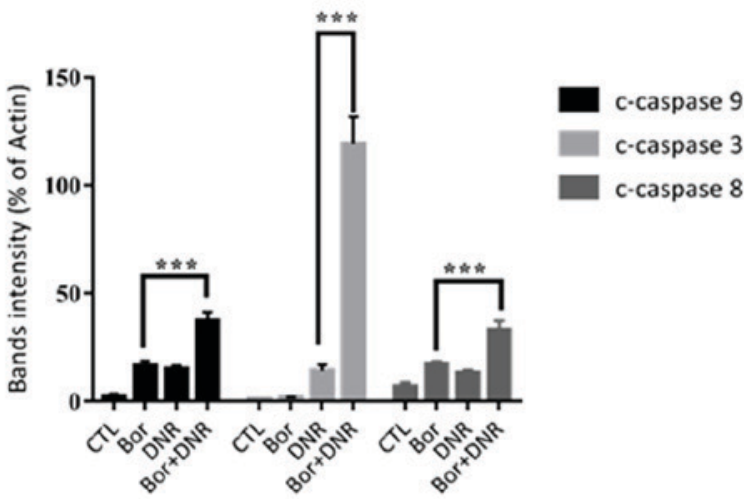

D

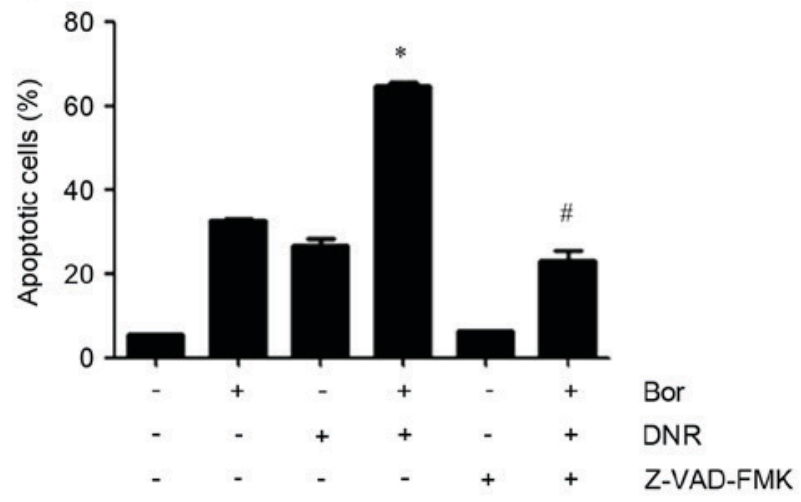

Figure 3. Activation of the caspase cascade by Bor+DNR in Jurkat and Molt-4 cells. (A) Jurkat and (B) Molt-4 cells were treated with Bor, with or without DNR, for $24 \mathrm{~h}$, and the indicated proteins were examined using western blot analysis. Relative intensity of the bands was normalized to $\beta$-actin. ${ }^{* * * *} \mathrm{P}<0.001$, with comparisons indicated by lines. (C) Jurkat and (D) Molt-4 cells were preincubated with or without caspase inhibitor (Z-VAD-FMK; $10 \mu \mathrm{M})$ for $1 \mathrm{~h}$ and then treated with Bor and DNR for $24 \mathrm{~h}$. The apoptotic cells were determined using Annexin V/propidium iodide staining. All values are expressed as the mean \pm standard deviation. Each experiment was performed at least 3 times independently. ${ }^{*} \mathrm{P}<0.05$ compared with Bor or DNR treatment alone; and ${ }^{\#} \mathrm{P}<0.05$ compared with Bor+DNR treatment. Bor, bortezomib; DNR, daunorubincin.

treated with bortezomib and daunorubicin in the presence or absence of the broad-spectrum caspase inhibitor, Z-VAD-FMK $(10 \mu \mathrm{M})$. The results of the flow cytometric analysis revealed that Z-VAD-FMK significantly attenuated the cell death induced by cotreatment with bortezomib and daunorubicin $(\mathrm{P}<0.05)$. These findings suggested that bortezomib and daunorubicin promoted apoptosis through activating caspase- $3,-8$ and -9 .

Bortezomib+daunorubicin causes marked dissipation of $\Delta \Psi m$ and increases the expression of Bim. The mitochondrial pathway is critical in the execution of apoptotic cell death, and the collapse of $\Delta \Psi \mathrm{m}$ is an early event in the mitochondrial cell death pathway. The present study examined alterations in $\Delta \Psi \mathrm{m}$ using rhodamine123/PI staining. Marked dissipation of $\Delta \Psi \mathrm{m}$ was observed in the Jurkat cells cotreated with bortezomib and daunorubicin at $24 \mathrm{~h}(35.4 \pm 9.3 \%)$, which was significantly higher, compared with that in the Jurkat cells treated with bortezomib $(11.1 \pm 4.6 \%)$ or daunorubicin $(9.3 \pm 2.0 \%)$ alone (Fig. 4A). Similar results were observed in Molt-4 cells (Fig. 4B). Alterations in the expression of the $\mathrm{Bcl}-2$ family proteins, $\mathrm{Bcl}-2, \mathrm{Bcl}-\mathrm{xl}$ and $\mathrm{Bim}$, were also examined. In the Jurkat cells, daunorubicin alone had no apparent effect, whereas bortezomib upregulated the expression of Bim. However, the combination of bortezomib and 
A

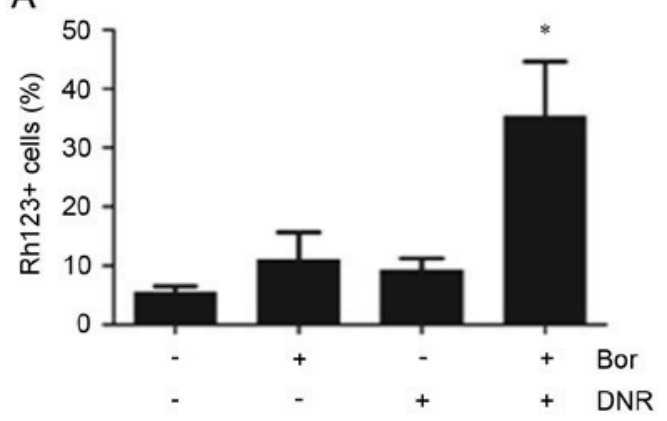

C

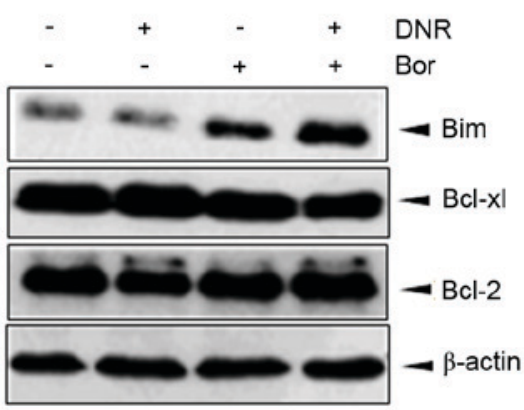

B

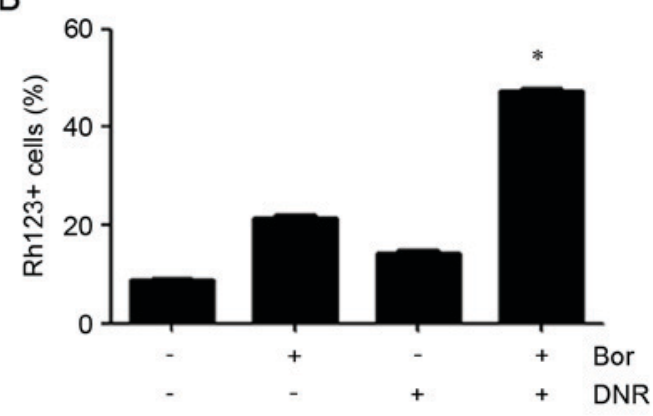

D

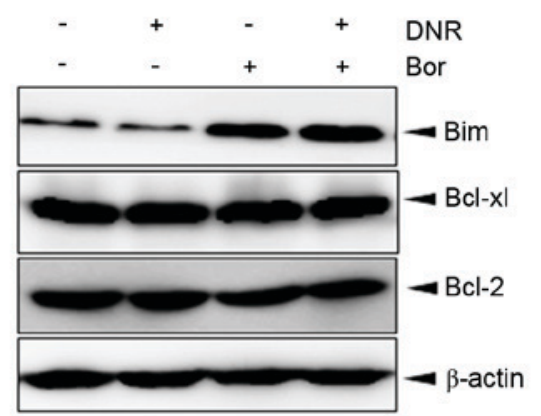

Figure 4. Effect of DNR+Bor on $\Delta \Psi \mathrm{m}$ and the expression of the Bcl-2 family proteins in Jurkat and Molt-4 cells. (A) Jurkat and (B) Molt-4 cells were treated with Bor with or without DNR for $24 \mathrm{~h}$. The $\Delta \Psi \mathrm{m}$ was determined using rhodamine123/propidium iodide double staining with flow cytometry. (C) Jurkat and (D) Molt-4 cells were treated with Bor and DNR for 6,12 and $24 \mathrm{~h}$, and total cellular extracts were subjected to western blot assays for the indicated proteins. Each experiment was performed at least 3 times independently. ${ }^{*} \mathrm{P}<0.05$, compared with Bor or DNR treatment alone. $\Delta \Psi \mathrm{m}$, mitochondrial membrane potential; Bor, bortezomib; DNR, daunorubincin; Bcl-2, B-cell lymphoma 2; Bim, Bcl-2-interacting mediator of cell death; Bcl-2-xl, Bcl-2 extra large.

A

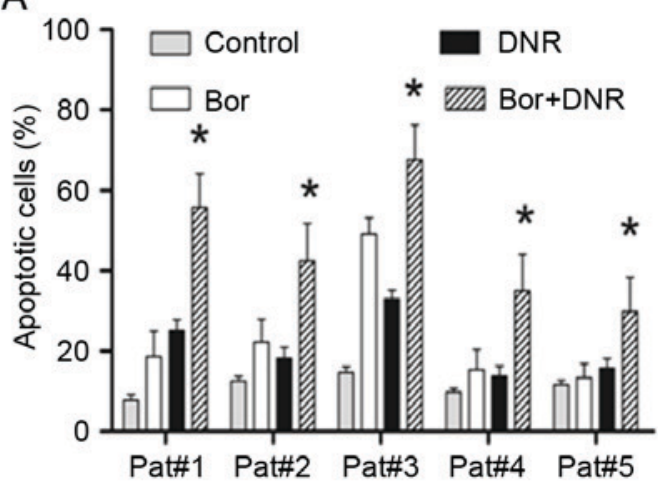

B

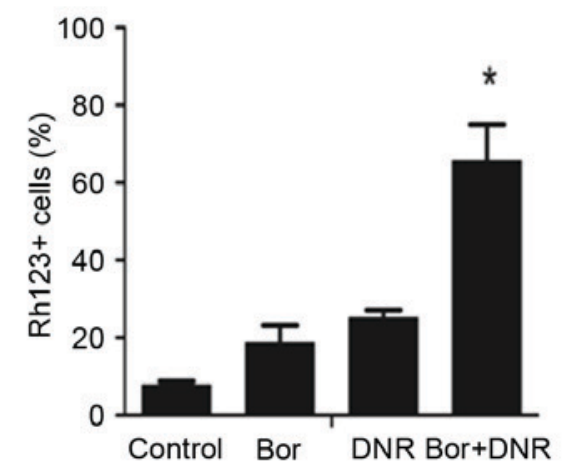

C

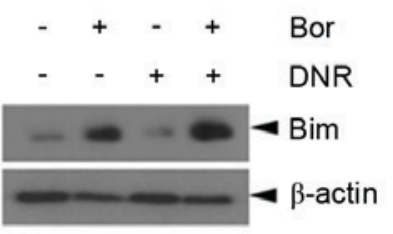

Figure 5. Combined effect of Bor+DNR in primary T-ALL cells. Primary blasts from five patients with T-ALL were exposed to Bor (10 nM) and DNR $(500 \mathrm{nM})$ for $24 \mathrm{~h}$, and the (A) apoptotic cells were determined using Annexin V/PI staining. (B) $\Delta \Psi \mathrm{m}$ was determined using rhodamine123/PI double staining with flow cytometry. (C) Indicated proteins were examined using western blot analysis. Data are expressed as the mean \pm standard deviation. Each experiment was performed at least 3 times independently. Images are representative of at least three independent experiments. "P<0.05, compared with Bor or DNR treatment. Bor, bortezomib; DNR, daunorubincin; PI, propidium iodide.

daunorubicin caused a marked increase in the expression of Bim at $24 \mathrm{~h}$ (Fig. 4C). By contrast, the combination regimen exerted no noticeable effect on the expression of Bcl-2 or Bcl-xl (Fig. 4C). Similar results were observed in the Molt-4 cells (Fig. 4D). These data indicated that the combination effect of bortezomib+daunorubicin was associated with the collaspe of $\Delta \Psi \mathrm{m}$, in which Bim may be involved.

Bortezomib and daunorubicin in combination are effective in inducing the apoptosis of primary T-ALL cells. To determine whether the combination effect of bortezomib and daunorubicin was limited to Jurkat cells, five primary T-ALL cells were treated with daunorubicin $(500 \mathrm{nM})$ in the presence or absence of bortezomib (10 nM) for $24 \mathrm{~h}$. As shown in Fig. 5A, bortezomib+daunorubicin caused a significantly higher apoptotic rate, compared with either agent used alone $(\mathrm{P}<0.05)$. In addition, flow cytometric analyses showed that bortezomib or daunorubicin alone caused only modest mitochondrial injury, whereas the combination of bortezomib and daunorubicin resulted in more prominent mitochondrial injury (Fig. 5B). Furthermore, the western blot assays showed that the combination treatment markedly increased 
the expression of Bim in primary ALL cells, compared with either bortezomib or daunorubicin alone (Fig. 5C). Together, these findings indicated that the combination of bortezomib and daunorubicin exerted more marked cytotoxicity against primary ALL cells by disrupting the $\Delta \Psi \mathrm{m}$.

\section{Discussion}

T-ALL has a poor prognosis due to its intrinsic chemoresistance and severe immunosuppression. Although traditional chemotherapeutic regimens have shown improved response rate, they have failed to achieve a significant effect on long-term survival rates (2). Therefore, novel strategies are required for the treatment of T-ALL. In the present study, it was demonstrated that bortezomib and daunorubicin cotreatment induced apoptosis in T-ALL cells via disrupting the $\Delta \Psi \mathrm{m}$.

Human leukemic cells express abnormally high levels of proteasomes, compared with normal peripheral blood cells, and they are significantly more sensitive to proteasome inhibition, compared with normal bone marrow progenitor cells or peripheral blood lymphocytes $(6,14,15)$. Clinical trials are underway to assess the efficacy of bortezomib in several human malignancies, including leukemia (10). Available data suggest that bortezomib as a single drug may only yield minor clinical benefits in patients with leukemia $(7,16)$. However, bortezomib has been shown to enhance the efficacy of several conventional therapies and may overcome resistance to conventional anticancer drugs, including belinostat, SAHA, gemcitabine and imatinib, and the effects in combination studies appear promising (10,17-24). In the present study, using human T-ALL Jurkat and Molt-4 cells as a model, it was demonstrated that bortezomib and daunorubicin cotreatment was more effective, compared with either agent used alone at inducing apoptosis, as reflected by the activation of caspase- $3,-8$ and -9 , and the appearance of apoptotic morphology. Notably, it was demonstrated that this combination effect was also present in primary T-ALL cells. It is well known that standard chemotherapy is inhibitory to normal hematopoietic cells and frequently results in severe myelosuppression, and anthracyclines can cause cumulative dose-dependent cardiotoxicity (25). Thus, the combination of bortezomib and daunorubicin at a lower dose may reduce their dose-associated side effect but increasing their efficacy. Similar to the findings obtained in the present study, Koyama et al reported that bortezomib and doxrubicin also induced apoptosis in T-ALL cell lines (26). However, the combination effect of these drugs on primary leukemia cells was not investigated.

The mitochondrial and cell death receptor apoptotic pathways are two major apoptotic cell death pathways. It has been shown that mitochondrial signaling exerts a critical role in bortezomib-induced apoptosis (27-30). The present study found that the combination of these two agents caused extensive loss of $\Delta \Psi \mathrm{m}$, indicating the involvement of the mitochondrial apoptotic pathway. Consistent with this, bortezomib and daunorubicin cotreatment enhanced the collapse of $\Delta \Psi \mathrm{m}$ in primary T-ALL leukemia cells. The cell death receptor pathway may also be activated by cotreatment of bortezomib and daunorubicin, as evidenced by the activation of caspase- 8 .

An important event in the mitochondrial apoptotic pathway is mitochondrial outer membrane permeabilization, which is primarily mediated and controlled by the Bcl-2 family members (31). When mitochondrial outer membrane permeabilization occurs, it precipitates cell death through either the release of molecules involved in apoptosis or the loss of mitochondrial functions essential for cell survival. The present study determined the effect of bortezomib daunorubicin cotreatment on several Bcl-2 family members. The bortezomib daunorubicin cotreatment markedly increased the proapoptotic regulator protein, Bim, in the Jurkat and primary ALL cells, but exerted minimal effect on the expression of Bcl-2 or $\mathrm{Bcl}-\mathrm{xl}$. Bim is a member of the $\mathrm{BH} 3$-only protein family, which mediates cell death from physiologic stimuli, including cytokine deprivation and signals from activated oncogenes. The upregulation of Bim triggers the release of cytochrome $c$ from the mitochondria and the onset of apoptosis (32). The results of the present study indicated that Bim may be important in bortezomib+daunorubicin-induced cell death. Consistent with this, several reports have shown that Bim-targeting contributes to the bortezomib-based combination regime (33-35). However, whether Bim contributed to bortezomib+daunorubicin-induced mitochondria impairment, and how cotreatment with bortezomib and daunorubicin upregulated the expression of Bim required further investigation. BH3-interacting domain death agonist (Bid), another proapoptotic Bcl-2 family member, may also be involved in this process $(36,37)$. As shown in Fig. 2, bortezomib and daunorubicin cotreatment induced the activation of caspase 8 . Caspase 8 can cleave Bid into t-Bid, which then causes mitochondrial outer membrane permeabilisation. This leads to the mitochondrial release of apoptogenic proteins, including cytochrome $c$.

In conclusion, the present demonstrated that bortezomib cooperated with daunorubicin to induce the apoptosis of Jurkat and Molt-4 cells, and primary T-ALL cells, in which the mitochondrial apoptotic pathway was pivotal. These findings provide a rationale for use of the combination of bortezomib and daunorubicin in the treatment T-ALL in future preclincal and clinical investigations.

\section{Acknowledgements}

This study was supported by the Shanghai Commission of Science and Technology (grant nos. 10411966900 and 15401901800), the National Natural Science Foundation of China (grant nos. 81170508, 31100980, 81570118 and 81570112) and the Innovation Program of Shanghai Municipal Education Commission (grant no. 13YZ028).

\section{References}

1. Pui CH, Robison LL and Look AT: Acute lymphoblastic leukaemia. Lancet 371: 1030-1043, 2008.

2. Bazarbachi A, Ghez D, Lepelletier Y, Nasr R, de Thé H, El-Sabban ME and Hermine O: New therapeutic approaches for adult T-cell leukaemia. Lancet Oncol 5: 664-672, 2004.

3. Marks DI and Rowntree C: Management of adults with T-cell lymphoblastic leukemia. Blood 129: 1134-1142, 2017.

4. Johnson DE: The ubiquitin-proteasome system: Opportunities for therapeutic intervention in solid tumors. Endocr Relat Cancer 22: T1-T17, 2015.

5. Kouroukis TC, Baldassarre FG, Haynes AE, Imrie K, Reece DE and Cheung MC: Bortezomib in multiple myeloma: Systematic review and clinical considerations. Curr Oncol 21: e573-e603, 2014. 
6. Orlowski RZ and Kuhn DJ: Proteasome inhibitors in cancer therapy: Lessons from the first decade. Clin Cancer Res 14: 1649-1657, 2008

7. Horton TM, Pati D, Plon SE, Thompson PA, Bomgaars LR, Adamson PC, Ingle AM, Wright J, Brockman AH, Paton M and Blaney SM: A phase 1 study of the proteasome inhibitor bortezomib in pediatric patients with refractory leukemia: A children's oncology group study. Clin Cancer Res 13: 1516-1522, 2007.

8. Bertaina A, Vinti L, Strocchio L, Gaspari S, Caruso R, Algeri M, Coletti V, Gurnari C, Romano M, Cefalo MG, et al: The combination of bortezomib with chemotherapy to treat relapsed/refractory acute lymphoblastic leukaemia of childhood. Br J Haematol 176: 629-636, 2017.

9. Howard DS, Liesveld J, Phillips GL II, Hayslip J, Weiss H, Jordan CT and Guzman ML: A phase I study using bortezomib with weekly idarubicin for treatment of elderly patients with acute myeloid leukemia. Leuk Res 37: 1502-1508, 2013

10. Messinger YH, Gaynon PS, Sposto R, van der Giessen J, Eckroth E, Malvar J and Bostrom BC; Therapeutic Advances in Childhood Leukemia \& Lymphoma (TACL) Consortium: Bortezomib with chemotherapy is highly active in advanced B-precursor acute lymphoblastic leukemia: Therapeutic Advances in Childhood Leukemia \& Lymphoma (TACL) study. Blood 120: 285-290, 2012.

11. Löwenberg B, Ossenkoppele GJ, van Putten W, Schouten HC, Graux C,Ferrant A, Sonneveld P, Maertens J,Jongen-Lavrencic M, von Lilienfeld-Toal M, et al: High-dose daunorubicin in older patients with acute myeloid leukemia. N Engl J Med 361: 1235-1248, 2009.

12. Pommier Y, Leo E, Zhang H and Marchand C: DNA topoisomerases and their poisoning by anticancer and antibacterial drugs. Chem Biol 17: 421-433, 2010.

13. Chou TC: Drug combination studies and their synergy quantification using the Chou-Talalay method. Cancer Res 70: 440-446, 2010.

14. Crawford LJ and Irvine AE: Targeting the ubiquitin proteasome system in haematological malignancies. Blood Rev 27: 297-304, 2013.

15. Soligo D, Servida F, Delia D, Fontanella E, Lamorte G, Caneva L, Fumiatti R and Lambertenghi Deliliers G: The apoptogenic response of human myeloid leukaemia cell lines and of normal and malignant haematopoietic progenitor cells to the proteasome inhibitor PSI. Br J Haematol 113: 126-135, 2001.

16. Du XL and Chen Q: Recent advancements of bortezomib in acute lymphocytic leukemia treatment. Acta Haematol 129 : 207-214, 2013.

17. Dai Y, Chen S, Wang L, Pei XY, Kramer LB, Dent P and Grant S: Bortezomib interacts synergistically with belinostat in human acute myeloid leukaemia and acute lymphoblastic leukaemia cells in association with perturbations in NF- $\mathrm{KB}$ and $\mathrm{Bim}$. Br J Haematol 153: 222-235, 2011.

18. Lieu C, Chow L, Pierson AS, Eckhardt SG, O'Bryant CL, Morrow M, Tran ZV, Wright JJ and Gore L: A phase I study of bortezomib, etoposide and carboplatin in patients with advanced solid tumors refractory to standard therapy. Invest New Drugs 27: 53-62, 2009

19. Walker AR, Klisovic RB, Garzon R, Schaaf LJ, Humphries K, Devine SM, Byrd JC, Grever MR, Marcucci G and Blum W: Phase I study of azacitidine and bortezomib in adults with relapsed or refractory acute myeloid leukemia. Leuk Lymphoma 55: 1304-1308, 2014.

20. Schelman WR, Traynor AM, Holen KD, Kolesar JM, Attia S, Hoang T, Eickhoff J, Jiang Z, Alberti D, Marnocha R, et al: A phase I study of vorinostat in combination with bortezomib in patients with advanced malignancies. Invest New Drugs 31: 1539-1546, 2013.

21. Messinger Y, Gaynon P, Raetz E, Hutchinson R, Dubois S, Glade-Bender J, Sposto R, van der Giessen J, Eckroth E and Bostrom BC: Phase I study of bortezomib combined with chemotherapy in children with relapsed childhood acute lymphoblastic leukemia (ALL): A report from the therapeutic advances in childhood leukemia (TACL) consortium. Pediatr Blood Cancer 55: 254-259, 2010

22. Hu Z, Pan XF, Wu FQ, Ma LY, Liu DP, Liu Y, Feng TT, Meng FY, Liu XL, Jiang QL, et al: Synergy between proteasome inhibitors and imatinib mesylate in chronic myeloid leukemia. PLoS One 4: e6257, 2009
23. Zhang QL, Wang L, Zhang YW, Jiang XX, Yang F, Wu WL, Janin A, Chen Z, Shen ZX, Chen SJ and Zhao WL: The proteasome inhibitor bortezomib interacts synergistically with the histone deacetylase inhibitor suberoylanilide hydroxamic acid to induce T-leukemia/lymphoma cells apoptosis. Leukemia 23: $1507-1514,2009$

24. Hui KF, Leung YY, Yeung PL, Middeldorp JM and Chiang AK: Combination of SAHA and bortezomib up-regulates CDKN2A and CDKN1A and induces apoptosis of Epstein-Barr virus-positive Wp-restricted Burkitt lymphoma and lymphoblastoid cell lines. Br J Haematol 167: 639-650, 2014.

25. Schimmel KJ, Richel DJ, van den Brink RB and Guchelaar HJ: Cardiotoxicity of cytotoxic drugs. Cancer Treat Rev 30: 181-191, 2004.

26. Koyama D, Kikuchi J, Hiraoka N, Wada T, Kurosawa H, Chiba S and Furukawa Y: Proteasome inhibitors exert cytotoxicity and increase chemosensitivity via transcriptional repression of Notch1 in T-cell acute lymphoblastic leukemia. Leukemia 28: $1216-1226,2014$

27. Song IS, Kim HK, Lee SR, Jeong SH, Kim N, Ko KS, Rhee BD and Han J: Mitochondrial modulation decreases the bortezomib-resistance in multiple myeloma cells. Int J Cancer 133: 1357-1367, 2013

28. Berges C, Haberstock H, Fuchs D, Sadeghi M, Opelz G, Daniel V and Naujokat C: Proteasome inhibition activates the mitochondrial pathway of apoptosis in human $\mathrm{CD}^{+} \mathrm{T}$ cells. J Cell Biochem 108: 935-946, 2009.

29. Grandjenette C, Schnekenburger M, Karius T, Ghelfi J, Gaigneaux A, Henry E, Dicato M and Diederich M: 5-aza-2'-deoxycytidine-mediated c-myc down-regulation triggers telomere-dependent senescence by regulating human telomerase reverse transcriptase in chronic myeloid leukemia. Neoplasia 16: 511-528, 2014.

30. Voortman J, Checinska A, Giaccone G, Rodriguez JA and Kruyt FA: Bortezomib, but not cisplatin, induces mitochondria-dependent apoptosis accompanied by up-regulation of noxa in the non-small cell lung cancer cell line NCI-H460. Mol Cancer Ther 6: 1046-1053, 2007.

31. Kroemer G, Galluzzi L and Brenner C: Mitochondrial membrane permeabilization in cell death. Physiol Rev 87: 99-163, 2007.

32. Akiyama T, Dass CR and Choong PF: Bim-targeted cancer therapy: A link between drug action and underlying molecular changes. Mol Cancer Ther 8: 3173-3180, 2009.

33. Wirth M, Stojanovic N, Christian J, Paul MC, Stauber RH, Schmid RM, Häcker G, Krämer OH, Saur D and Schneider G: MYC and EGR1 synergize to trigger tumor cell death by controlling NOXA and BIM transcription upon treatment with the proteasome inhibitor bortezomib. Nucleic Acids Res 42: 10433-10447, 2014

34. Chen S, Zhang Y, Zhou L, Leng Y, Lin H, Kmieciak M, Pei XY, Jones R, Orlowski RZ, Dai Y and Grant S: A Bim-targeting strategy overcomes adaptive bortezomib resistance in multiple myeloma through a novel link between autophagy and apoptosis. Blood 124: 2687-2697, 2014.

35. Pigneux A, Mahon FX, Moreau-Gaudry F, Uhalde M, de Verneuil H, Lacombe F, Reiffers J, Milpied N, Praloran V and Belloc F: Proteasome inhibition specifically sensitizes leukemic cells to anthracyclin-induced apoptosis through the accumulation of Bim and Bax pro-apoptotic proteins. Cancer Biol Ther 6: 603-611, 2007

36. Premkumar DR, Jane EP, DiDomenico JD, Vukmer NA, Agostino NR and Pollack IF: ABT-737 synergizes with bortezomib to induce apoptosis, mediated by Bid cleavage, Bax activation, and mitochondrial dysfunction in an Akt-dependent context in malignant human glioma cell lines. J Pharmacol Exp Ther 341: 859-872, 2012.

37. Unterkircher T, Cristofanon S, Vellanki SH, Nonnenmacher L, Karpel-Massler G, Wirtz CR, Debatin KM and Fulda S: Bortezomib primes glioblastoma, including glioblastoma stem cells, for TRAIL by increasing tBid stability and mitochondrial apoptosis. Clin Cancer Res 17: 4019-4030, 2011. 